\title{
PERAN INFORMAL KELUARGA DALAM PENGENDALIAN KADAR GLUKOSA DARAH PADA PENDERITA DIABETES MELLITUS
}

\author{
Lusy Farida $^{1)}$, Puji Purwaningsih ${ }^{2)}$, Rosalina ${ }^{3)}$ \\ Universitas Ngudi Waluyo Ungaran \\ Email: duorais@gmail.com
}

\begin{abstract}
Diabetes mellitus is a disease or disorder of chronic metabolism with multiethiology characterized by high blood sugar (hyperglycemia). Diabetes Mellitus can not be cured but can be controlled by regulating blood sugar levels. One important factor in controlling blood sugar levels is the role of the family

To know the correlation between family's informal role and the control of blood glucose levels in people with diabetes mellitus at RSUD Ungaran Semarang Regency.

The design of this study was descriptive correlational with cross sectional approach with the number of population of 176 people and samples of 64 respondents by using accidental sampling method. Data collection tools used questionnaires. Data analysis used SPSS version 23.0. Bivariate analysis was processed by using chi square test.

The informal role of the family in people with diabetes mellitus is mostly in good category (75.0\%). Control of blood glucose level in people with diabetes mellitus is mostly in good category $(62,5 \%)$. There is significant correlation between family informal role and blood glucose control in patients with diabetes mellitus at RSUD Ungaran Semarang Regency, with $p$ value 0,043<0,05 ( $\alpha$ ).

There is correlation between family's informal role and the control of blood glucose levels in people with diabetes mellitus at RSUD Ungaran Semarang Regency.

We recommend that patients with DM further improve the control of blood glucose levels by increasing the role of the family so as to prevent the occurrence of complications
\end{abstract}

Keywords: informal family role, blood glucose control, DM patient

Literature: 35 (2006-2015)

\section{LATAR BELAKANG}

Diabetes melitus merupakan penyakit selama hidup, maka pengawasan dan pemantauan dalam penatalaksanaan diabetes melitus pada setiap saat menjadi penting. Oleh karena itu maka penatalaksanaan penderita diabetes melitus tidak dapat sepenuhnya diletakkan pada pundak dokter dan klinis saja. Dalam hal ini peran penderita diabetes melitus dan keluarganya sangat diperlukan khususnya dalam pengontrolan kadar gula darah pada penderita diabetes melitus ke dalam situasi sehat atau paling tidak mendekati normal (Waspadji, 2009).

American Diabetes Association (2008), mengatakan bahwa perencanaan pengelolaan diabetes harus dibicarakan sebagai teraupetik antara pasien dan keluarganya. Pasien harus menerima perawatan medis secara terkoordinasi dan integrasi dari Tim kesehatan, sehingga keluarga menyadari pentingnya keikutsertaan dalam perawatan penderita diabetes melitus agar kadar gula darah penderita dapat terkontrol dengan baik. Menurut Meiner (2011) sehat dan sakit dipengaruhi oleh budaya, keluarga, sosial ekonomi dan lingkungan. Pengaruh keluarga terhadap sehat dan sakit berkaitan dengan peran dan fungsi keluarga. Keluarga memainkan peran yang sangat signifikan terhadap kehidupan keluarga yang lain terutama status sehat sakit.

Peran keluarga terdiri dari peran formal dan peran informal. Dalam peran 
informal keluarga terdapat peran merawat keluarga dan peran memotivasi/ pendorong keluarga (Friedman, 2010). Peran formal keluarga yaitu peran parental dan perkawinan yang terdiri dari peran penyedia, peran pengatur rumah tangga, perawatan anak, peran persaudaraan, dan peran seksual. Peran informal keluarga bersifat implisit dan tidak tampak kepermukaan dan hanya diperankan untuk menjaga keseimbangan keluarga, sepeti pendorong, inisiatif, pendamai, penghalang, pengikut, pencari pengakuan, sahabat, koordinator keluarga dan penghubung (Padila, 2012).

Keluarga merupakan peran utama dalam pemeliharaan kesehatan dan membantu pasien dalam perawatan dan pengendalian diabetes melitus, memberikan semangat dan motivasi pada pasien, agar melanjutkan hidupnya, meyakinkan pasien bahwa mereka juga bagian penting, dibutuhkan dan dinginkan dalam keluarga, meyakinkan bahwa banyak orang yang berhasil mengontrol kadar gula darah kemudian melakukan aktivitas normal. Perencanaan pengelolaan diabetes melitus harus dilakukan secara bersama antara pasien dengan keluarga agar kadar gula darah dapat terkontrol. Perawatan pasien diabetes melitus memerlukan peranan keluarga dalam mengelola anggota keluarganya (Waspandji, 2009).

Berdasarkan hasil studi pendahuluan yang dilakukan oleh peneliti pada bulan November 2017 di RSUD Ungaran yaitu melakukan pengukuran terkait dengan variabel Peran Keluarga dengan Pengendalian Kadar Glukosa Darah pada Penderita Diabetes Mellitus terhadap 8 pasien diperoleh 5 pasien tidak melakukan diet makan, jarang olah raga dan tidak aktif beribadah (glukosa darah sewaktu dalam 5 bulan terakhir cenderung meningkat dengan rata-rata antara $136-279 \mathrm{mg} / \mathrm{dl}$ ) dimana 3 orang menyatakan keluarga mendorong untuk melakukan pemeriksaan gula darah sesuai jadwal, memberikan pujian ketika dapat menjaga kadar glukosa darah dan menemani saat melakukan olah raga dan 2 orang menyatakan keluarga mendorong untuk melakukan pemeriksaan gula darah sesuai jadwal, memberikan pujian ketika dapat menjaga kadar glukosa darah dan menemani saat melakukan olah raga.

Peneliti juga memperoleh 3 pasien melakukan diet makan, olah raga dan aktif beribadah (glukosa darah sewaktu dalam 5 bulan terakhir cenderung stabil dengan rata-rata antara 81-16 $\mathrm{mg} / \mathrm{dl}$ ) dimana seorang menyatakan keluarga mendorong untuk melakukan pemeriksaan gula darah sesuai jadwal, memberikan pujian ketika dapat menjaga kadar glukosa darah dan menemani saat melakukan olah raga dan 2 orang menyatakan keluarga mendorong untuk melakukan pemeriksaan gula darah sesuai jadwal, memberikan pujian ketika dapat menjaga kadar glukosa darah dan menemani saat melakukan olah raga. Peneliti mendapatkan informasi bahwa mereka juga aktif memeriksakan kadar glukosa darah setiap bulannya minimal satu kali, melakukan olah raga dengan teratur sesuai dengan ajuran tenaga kesehatan. Hal tersebut menunjukkan bahwa pengendalian glukosa pada pasien sebagian besar buruk meskipun keluarga memberikan dukungan yang optimal

\section{METODE PENELITIAN}

Penelitian ini merupakan penelitian deskriptif korelasi. digunakan dalam penelitian ini adalah dengan pendekatan cross sectional.Populasi dalam penelitian ini adalah penderita diabetes mellitus di RSUD Ungaran Kabupaten Semarang, yaitu sebanyak 176 orang (data Bulan Mei 2018) dengan sampel dalam penelitian ini sebanyak 64 orang. Teknik pengambilan sampel yang digunakan dalam penelitian ini adalah accidental sampling. Penelitian ini telah dilakukan di instalasi rawat jalan RSUD Ungaran Kabupaten Semarang pada tanggal 2-23 Juni 2018. alat pengumpulan data yang digunakan dalam penelitian ini berupa 
kuesioner. Analisis bivariat pc $c$ Peran Pengendalian Kadar GD

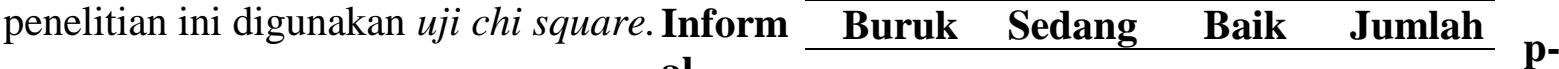

HASIL PENELITIAN

A. Analisa Univariat

1. Gambaran Peran Informal Keluargarang $9 \begin{array}{lllllllll} & 96,3 & 5 & 31,3 & 2 & 12,5 & 16 & 100 & 0,04\end{array}$ pada Penderita Diabetes Mellitus di RSUD Ungaran KabupatBaik Semarang

Tabel 1 Distribusi Frekuensi PercJumla $21 \quad 32,8 \quad 22 \quad 34,4$

Informal Keluarga pada Penderih

Diabetes Mellitus di RSUD Ungaran

Kabupaten Semarang

\begin{tabular}{lcc}
\hline $\begin{array}{c}\text { Peran } \\
\text { informal } \\
\text { keluarga }\end{array}$ & $\begin{array}{c}\text { Frekuen } \\
\text { si } \\
\text { (f) }\end{array}$ & $\begin{array}{c}\text { Persentase } \\
(\%)\end{array}$ \\
\hline Kurang & 16 & 25,0 \\
\hline Baik & 48 & 75,0 \\
\hline Jumlah & 64 & 100,0 \\
\hline \multicolumn{2}{c}{ Berdasarkan } & Tabel 1
\end{tabular}

menunjukkanperan informal keluarga pada penderita diabetes mellitus di RSUD Ungaran Kabupaten Semarang sebagian besar kategori baik yaitu sebanyak 48 orang $(75,0 \%)$.

2. Gambaran Pengendalian Kadar Glukosa Darah pada Penderita Diabetes Mellitus di RSUD Ungaran Kabupaten Semarang

\begin{tabular}{|c|c|c|}
\hline $\begin{array}{c}\text { Pengendalia } \\
\text { n Kadar } \\
\text { Glukosa } \\
\text { Darah } \\
\end{array}$ & $\begin{array}{c}\text { Frekuens } \\
\text { i } \\
\text { (f) }\end{array}$ & $\begin{array}{c}\text { Persentas } \\
\text { e } \\
(\%)\end{array}$ \\
\hline Buruk & 21 & 32,8 \\
\hline Sedang & 22 & 34,4 \\
\hline Baik & 21 & 32,8 \\
\hline Jumlah & 64 & 100,0 \\
\hline \multicolumn{3}{|c|}{ Berdasarkan } \\
\hline \multicolumn{3}{|c|}{$\begin{array}{l}\text { menunjukkan pengendalian kadar } \\
\text { glukosa darah pada penderita diabetes }\end{array}$} \\
\hline mellitus di & RSUD & Ungaran \\
\hline Kabupaten Ser & marang $\mathrm{pa}$ & ng banyak \\
\hline & ng yaitu & banyak 22 \\
\hline
\end{tabular}

B. Analisa Bivariat

Tabel 3 Hubungan Peran Informal Keluarga dengan Pengendalian Kadar Glukosa Darah Pada Penderita Diabetes Mellitus di RSUD Ungaran Kabupaten Semarang.

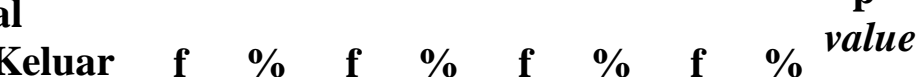

,0 3

$\begin{array}{llllllll}12 & 25,0 & 17 & 35,4 & 19 & 39,6 & 48 & 100\end{array}$

, 0

$\begin{array}{cccc}21 & 32,8 & 64 & 100 \\ 0\end{array}$

Tabel 3 menunjukkan

Berdasarkan hasil analisis hubungan peran informal keluarga dengan pengendalian kadar glukosa darah pada penderita diabetes mellitus di RSUD UngaranKabupaten Semarang, diperoleh hasil responden yang mendapatakan peran informal keluarga kategori kurang sebanyak 16 orang dimana yang mempunyai pengendalian kadar glukosa darah kategori buruk yaitu sebanyak 9 orang $(56,3 \%)$ sedangkan kategori cukup yaitu sebanyak 5 orang $(31,3 \%)$ dan kategori baik yaitu sebanyak 2 orang (12,5\%). Diperoleh hasil responden yang mendapatakan peran informal keluarga kategori baik sebanyak 48 orang dimana yang mempunyai pengendalian kadar glukosa darah kategori baik yaitu sebanyak 19 orang $(39,6 \%)$, sedangkan kategori sedang yaitu sebanyak 17 orang $(35,4 \%)$ dan lebih banyak dari pada kategori buruk yaitu sebanyak 12 orang $(25,0 \%)$.

Hasil uji statistik dengan menggunakan uji chi square didapatkan pvalue sebesar 0,043 < $0,05(\alpha)$, maka dapat disimpulkan ada hubungan peran informal keluarga dengan pengendalian kadar glukosa darah pada penderita diabetes mellitus di RSUD Ungaran Kabupaten Semarang.

\section{PEMBAHASAN}




\section{A. Gambaran Peran Informal Keluarga pada Penderita Diabetes Mellitus di RSUD Ungaran Kabupaten Semarang.}

Hasil penelitian menunjukkan peran informal keluarga pada penderita diabetes mellitus di RSUD Ungaran Kabupaten Semarang kategori kurang yaitu sebanyak 16 orang $(25,0 \%)$. Peran informal keluarga pada penderita diabetes mellitus di RSUD Ungaran Kabupaten Semarang kategori kurang pada indikator peran informal sebagai konselor yang ditunjukkan dengan responden yang menjawab keluarga kadang-kadang memberikan gambaran ketika penderita DM melanggar diet makan (62,5\%), keluarga kadang-kadang memberikan pertimbangan jenis makanan yang dapat dikonsusmi $(59,4 \%)$, keluarga kadang-kadang sabar dalam membimbing pasien untuk berolahraga $(61,3 \%)$, keluarga kadang-kadang mengendalikan dan memberikan kesempatan pasien untuk minum air minum yang manis $(61,3 \%)$.

Keluarga memainkan peran yang sangat signifikan terhadap kehidupan keluarga yang lain terutama status sehat sakit. Menurut Meiner (2011), sehat dan sakit dipengaruhi oleh budaya, sosial ekonomi dan lingkungan serta keluarga. Pengaruh keluarga terhadap sehat dan sakit berkaitan dengan fungsi dan peran keluarga. Menruut Friedman (2010), peran keluarga terdiri dari peran formal dan peran informal. Dalam peran informal keluarga terdapat peran merawat keluarga dan peran memotivasi/ pendorong keluarga.

Hasil penelitian menunjukkan keluarga penderita DM tidak memberikan peran secara optimal. Mereka hanya menjalankan peran tidak sepenuh hati dimana tidak mendukung diet makan dan minum dan aktivitas olah raga. Menurut Sukardji (2012), mempertahankaan kadar gula darah agar mendekati nilai normal dapat dilakukan dengan asupan makanan yang seimbang sesuai dengan kebutuhan. Menurut Ilyas(2015), olah raga dapat meningkatkan sensitifitas jaringan terhadap insulin sehingga kadar glukosa lebih terkendali. Penelitian dari Sari (2014) yang menunjukkan peran keluarga klien DM yang berobat di Klinik Bratang Tangkis Surabaya adalah dalam pengaturan diet DM, pengaturan latihan fisik, pengaturan manajemen obat, pemantauan kadar gula darah, deteksi dini tanda/gejala komplikasi.

Responden menyatakan bahwa peran keluarga terhadap mereka kurang dalam mendukung diet. Menurut Wulan (2014), peran keluarga untuk mendukung diet penderita DM diantaranya mengatur, merencanakan, menyiapkan, mengingatkan dan mengawasi pola makan anggota keluarganya yang sakit DM, dengan cara mengatur, mengingatkan jadwal makan, merencanakan dan menyiapkan menu makanan serta mengawasi jumlah porsi dan jenis makanan yang boleh dimakan.

Responden menyatakan bahwa peran keluarga terhadap mereka kurang dalam mendukung aktifitas olah raga. Menurut Wulan (2014), peran keluarga untuk mendukung aktifitas fisik penderita DM peran yang mendorong / mengingatkan / mengajak anggota keluarganya yang sakit DM tersebut untuk melakukan latihan fisik di rumah secara rutin. Selain itu ada keluarga yang berperan sebagai pendamping saat olahraga, dan ada juga yang berperan jamak yaitu sebagai motivator sekaligus pendamping. Pendamping yang dimaksud adalah peran yang 
menemani klien DM saat berolahraga ikut berolahraga bersama.

Diabetes melitus bila tidak ditangani dengan baik akan mengakibatkan komplikasi pada berbagai organ tubuh seperti mata, ginjal, jantung, pembuluh kaki, syaraf dan lain-lain. maka itu sebelum terjadi komplikasi yang lebih lanjut, maka pengobatan dan penatalaksanaan pada pasien diabetes melitus harus dilakukan. Peran keluarga sangat dibutuhkan untuk mencapai kesehatan yang maksimal, untuk mencapai tujuan hidup sehat keikutsertaan pasien dan keluarga dalam mengelola penatalaksanaan kadar gula darah menjadi sangat penting agar gula darah pasien terkendali (Rifki, 2009).

Hasil penelitian menunjukkan responden menyatakan bahwa peran informal keluarga yang kurang disebabkan keluarga mereka adalah seorang pekerja swasta yaitu sebanyak 16 orang $(100,0 \%)$. Keluarga responden bekerja sebagai karyawan swasta yaitu pekerja pabrik yang ada di Kabupaten ataupun Kota Semarang. Sebagai seorang pekerja swasta biasanya mereka harus bekerja sesuai dengan kebijakan perusahaan termasuk harus bekerja lembur baik dalam hari kerja atau hari libur. Hal ini yang menyebabkan mereka tidak mempunyai waktu untuk memberikan perawatan bagi keluarganya yang mengalami DM sehingga perannyapun cenderung kurang.

Pekerjaan menyebabkan keterbatasan waktu interaksi antara keluraga dengan penderita DM. Menurut Brunner \& Suddarth (2012), keluarga yang mempunyai waktu lebih banyak dalam merawat anggota keluarga yang sakit tanpa harus meninggalkan pekerjaan formalnya lainnya bermanfaat untuk mempertahankan interaksi keluarga selama pasien di rawat di rumah sehingga jalinan komunikasi dalam keluarga tidak terputus. Menurut peneliti keluarga yang bekerja mengalami keterbatasan waktu berinteraksi dan komunikasi dengan penderita DM. hal tersebut menyebabkan mereka tidak dapat mengawasi diit yang harus dilakukan oleh penderita DM. keluraga juga tidak dapat mendampingi penderita DM berolah raga karena kewajiban aktivitas dalam bekerja.

Hasil penelitian menunjukkan peran informal keluarga pada penderita diabetes mellitus di RSUD Ungaran Kabupaten Semarang kategori baik yaitu sebanyak 48 orang $(75,0 \%)$.Peran informal keluarga pada penderita diabetes mellitus di RSUD Ungaran Kabupaten Semarang kategori baik pada indikator peran informal sebagai komunikator yang ditunjukkan dengan responden yang menjawab keluarga sering membicarakan perawatan penderita DM dengan terbuka $(68,4 \%)$, keluarga sering menegur dengan sopan ketika penderita melanggar advis tenaga kesehatan (70,3\%), keluarga sering mendiskusikan masalah yang dialami $(68,4 \%)$ dan keluarga selalu berupaya memahami keinginan dan kebutuhan penderita DM $(74,6 \%)$.

Keluarga merupakan peran utama dalam pemeliharaan kesehatan dan membantu pasien dalam perawatan dan pengendalian diabetes melitus. Menurut Valery (2014), perencanaan pengelolaan diabetes melitus harus dilakukan secara bersama antara pasien dengan keluarga agar kadar gula darah dapat terkontrol. Dalam perawatan pasien diabetes melitus diperlukan peranan keluarga dalam mengelola anggota keluarganya (Waspandji, 2009).

Keluarga mempunyai peran yang penting dalam perawatan penderita DM di rumah secara mandiri. 
Keikutsertaan anggota keluarga dalam memandu pengobatan, diet, latihan jasmani, pengisian waktu luang dan motivasi merupakan bentuk peran aktif bagi keberhasilan penatalaksanaan DM. Menurut Friedman (2008), peran keluarga yang baik terhadap penderita DM tidak terlepas dari faktor pendidikan.

Hasil penelitian menunjukkan bahwa responden yang menyatakan peran informal keluarga kategori baik sebanyak 48 orang dimana sebagian besar mempunyai pendidikan atas (SMA, SMK) yaitu sebanyak 22 orang $(45,8 \%)$ dan pendidikan tinggi sebanyak 4 orang $(8,3 \%)$. Pendidikan yang tinggi sangat menentukan perannya dalam keluarga. Anggota keluarga dengan pendidikan yang tinggi lebih mudah menerima informasi bahkan aktif menggali informasi termasuk yang berkaitan dengan peran bagi keluarga yang mempunyai anggota menderita DM. Semakin banyak informasi yang mereka dapatnya maka semakin baik pengetahuannya yang akhirnya mendukung mereka untuk mempunyai peran yang baik bagi anggota keluarga yang menderita DM. Pendidikan mendukung peningkatan pengetahuan keluarga tentang perannya bagi penderita DM. Menurut Friedman (2008), tingkat pendidikan yang baik akan meningkatkan pemahaman keluarga terhadap prosedur-prosedur yang harus dijalani penderita selama di rawat secara mandiri di rumah. Tingkat pendidikan yang baik mendukung peningkatan pengetahuan terhadap perawatan penderita DM dan memudahkan dokter, perawat dan tim kesehatan lainnya dalam memberikan instruksi. Pengetahuan yang baik mendukung sikap dan perilaku yang baik dalam berpartisipasi mendukung penatalaksanaan penderita DM.

\section{B. Pengendalian Kadar Glukosa Darah pada Penderita Diabetes Mellitus di RSUD Ungaran Kabupaten Semarang}

Hasil penelitian menunjukkan pengendalian kadar glukosa darah pada penderita diabetes mellitus di RSUD Ungaran Kabupaten Semarang kategori sedang yaitu sebanyak 22 orang $(34,4 \%)$. Glukosa darah kategori sedang ditunjukkan dengan glukosa rata-rata sebesar 138 $\mathrm{mg} / \mathrm{dL}$, sebesar $171 \mathrm{mg} / \mathrm{dL}$, sebesar $173 \mathrm{mg} / \mathrm{dL}$.

Kadar gula di dalam darah selalu fluktuatif bergantung pada asupan makanan. Kadar paling tinggi tercapai pada satu jam sesudah makan. Satu jam setelah makan, gula di dalam darah akan mencapai kadar paling tinggi, normalnya tidak melebihi 180 mg per $100 \mathrm{cc}$ darah $(180 \mathrm{mg} / \mathrm{dL})$. Kadar $180 \mathrm{mg} / \mathrm{dL}$ disebut ambang ginjal dimana ginjal bisa menahan gula pada kadar tersebut. Lebih dari angka tersebut ginjal tidak dapat menahan gula dan kelebihan gula akan keluar bersama urin, jadilah kencing yang manis (Murray et al., 2013). Pada penderita DM, kadar gula darah puasanya lebih dari $126 \mathrm{mg} / \mathrm{dL}$ dan gula darah sewaktu lebih dari 200 mg/dl (Murray et al., 2013).

Hasil penelitian menunjukkan pengendalian kadar glukosa darah pada penderita diabetes mellitus di RSUD Ungaran Kabupaten Semarang kategori sedang yaitu sebanyak 22 orang dimana sebagian besar mendapatkan informasi pertama kali tentang pengendalian glukosa darah dari tenaga kesehatan yaitu 13 orang $(59,1 \%)$ lebih banyak dari pada yang mendapat informasi pertama dari non tenaga kesehatan yaitu sebanyak 9 orang (40,9\%). Responden yang terpapar informasi pengendalian kadar glukosa darah pada penderita diabetes mellitus dari 
tenaga kesehatan biasanya lebih lengkap dan akurat sehingga kepedulian mereka terhadap glukosa sangat tinggi yang pada akhirnya meningkatkan perilaku mereka dalam mengedalikan glukosa darah.

Hasil penelitian menunjukkan pengendalian kadar glukosa darah pada penderita diabetes mellitus di RSUD Ungaran Kabupaten Semarang kategori baik yaitu sebanyak 21 orang $(32,8 \%)$. Glukosa darah kategori baik ditunjukkan dengan glukosa rata-rata sebesar 187 $\mathrm{mg} / \mathrm{dL}$, sebesar $228 \mathrm{mg} / \mathrm{dL}$, sebesar $229 \mathrm{mg} / \mathrm{dL}$.

Kontrol DM yang buruk dapat mengakibatkan hiperglikemia dalam jangka panjang, yang menjadi pemicu beberapa komplikasi yang serius baik makrovaskular maupun mikrovaskular seperti penyakit jantung, penyakit vaskuler perifer, gagal ginjal, kerusakan saraf dan kebutaan.Banyaknya komplikasi yang mengiringi penyakit DM telah memberikan kontribusi terjadinya perubahan fisik, psikologis maupun sosial (Anani 2012). Menurut (Notoatmodjo, 2010), faktor yang berhubungan perilaku seseorang diantaranya pendidikan.

Penderita diabetes mellitus di RSUD Ungaran Kabupaten Semarang mempunyai pengendalian kadar glukosa darah kategori baik sebanyak 21 orang $(32,8 \%)$ dimana sebagian besar mempunyai pendidikan yang baik yaitu pendidikan atas (SMA, SMK) yaitu sebanyak 10 orang $(47,6 \%)$ dan pendidikan tinggi (S1) yaitu sebanyak 2 orang $(9,5 \%)$ lebih banyak dari pada yang berpendidikan rendah (SD, SMP) yaitu sebanyak 9 orang $(42,9 \%)$. Pendidikan yang tinggi sangat menentukan kemampuan seseorang dalam menyerap informasi yang diberikan. Penderita DM yang mempunyai pendidikan yang baik lebih mudah menerima informasi bahkan aktif menggali informasi termasuk terkait dengan pengendalian glukosa darah, sehingga mereka melakukan pengendalian dengan penuh kesadaran tanpa harus mendapat intervensi dari orang lain.

Penderita yang mempunyai pendidikan yang baik cenderung dapat mengendalikan glukosa darahnya. Menurut Notoatmodjo (2010), pendidikan merupakan upaya persuasi atau pembelajaran kepada masyarakat agar mau melakukan tindakan-tindakan untuk memelihara atau mengatasi masalah-masalah, dan meningkatkan kesehatannya. Pendidikan mempunyai kaitan yang tinggi terhadap perilaku pasien untuk menjaga dan meningkatkan kesehatannya. Pendidikan bagi pasien DM berhubungan dengan perilaku pasien dalam melakukan pengendalian terhadap kadar glukosa darah agar tetap stabil. Hasil atau perubahan perilaku dengan cara ini membutuhkan waktu yang lama, namun hasil yang dicapai bersifat tahan lama karena didasari oleh kesadaran sendiri.

\section{Hubungan Peran Informal Keluarga dengan Pengendalian Kadar Glukosa Darah Pada Penderita Diabetes Mellitus}

Berdasarkan hasil analisis hubungan peran informal keluarga dengan pengendalian kadar glukosa darah pada penderita diabetes mellitus di RSUD UngaranKabupaten Semarang, diperoleh hasil responden yang mendapatakan peran informal keluarga kategori kurang dan mempunyai pengendalian kadar glukosa darah kategori sedang $(31,3 \%)$. Responden jarang menegur ketika penderita DM melanggar diet makan, memberikan pertimbangan jenis makanan yang dapat dikonsumsi sehingga glukosa rata-rata dalam 
enam bulan terakhir sebesar 138 $\mathrm{mg} / \mathrm{dL}$.

Pengendalian glukosa darah merupakan suatu pengendalian glukosa darah pasien DM (DM). Kontrol ini dilakukan setiap 1 bulan sekali yang meliputi pemeriksaan kontrol kadar gula darah puasa, kadar gula postprandial, serta kadar HbA1c. Apabila tidak diakukan secara teratur, dapat menyebabkan komplikasi sehingga penting dilakukan (Rachmawati, 2015).

Kontrol DM yang buruk dapat mengakibatkan hiperglikemia dalam jangka panjang, yang menjadi pemicu beberapa komplikasi yang serius baik makrovaskular maupun mikrovaskular seperti penyakit jantung, penyakit vaskuler perifer, gagal ginjal, kerusakan saraf dan kebutaan.Banyaknya komplikasi yang mengiringi penyakit DM telah memberikan kontribusi terjadinya perubahan fisik, psikologis maupun sosial (Anani 2012). Pengelolaan DM yang tidak dilakukan dengan baik, khususnya dalam hal pengendalian kadar glukosa darah dapat menimbulkan komplikasi pada pembuluh darah otak, mata, jantung, ginjal dan kaki yang mengakibatkan kejadian kebutaan, gagal ginjal, penyakti kardiovakuler, stroke serta amputasi pada kaki (Soegondo, 2015). Pengendalian kadar glukosa darah penderita DM dipengaruhi oleh pengetahuan keluarga tentang DM.

Meningkatkan pengetahuan tentang diabetes dan aset psikososial keluarga bermanfaat untuk mempromosikan perilaku kesehatan keluarga yang positif otomatis juga pasien DM (Gefter, Rosas, Rodriguesz, Morioka Dauglas, 2013). Melibatkan anak-anak dan orang tua selaku anggota keluarga dalam managemen diabetes meningkatkan pengetahuan dan perilaku yang dapat bermanfaat dalam mengelola pasien
DM (Sullivan, Bova, Johnson, Cullen, Jaffarian dan Quinn, 2014).

Sebaiknya keluarga mempunyai pengetahuan tentang apa saja faktor risiko yang dapat memengaruhi kadar gula darah bisa naik (hiperglikemia) atau turun (hipoglikemia) diantaranya yaitu cara pengendalian stres, infeksi, kaki diabetes, gangguan ginjal, diabetes dengan kehamilan, diabetes dengan ibadah puasa, diabetes yang menggunakan steroid, gangguan ginjal. Rendahnya kontrol gula darah pada DM tipe 2 yang menggunakan insulin yaitu gaya hidup, psikososial emosional, faktor yang berhubungan dengan pengobatan dan pengetahuan yang kurang (Tong \& Vethakkan, 2015).

Intervensi pendidikan pada keluarga dapat memberikan dukungan emosional dan psikologis membantu mempromosikan perilaku yang sehat. Meningkatkan pengetahuan keluarga otomatis meningkatkan pengetahuan pasien DM, karena itu agar berhasil pengelolaan pengendalian kadar gula darah pasien DM tipe 2 maka melibatkan anggota keluarga dalam setiap kontrol rutin di pelayanan kesehatan mutlak diperlukan mengingat sebagian pasien DM tipe 2 adalah orang lanjut usia yang sudah mengalami sebagian kemunduran organ fisiologisnya seperti penglihatan, pendengaran dan memori. Pengetahuan lain yang harus ditingkatkan baik pasien maupun keluarga adalah seperti pengendalian penyebabnya, yang meliputi pengendalian kenaikan berat badan bisa mengarah kepada timbulnya obesitas, pengendalian timbulnya komplikasi penyakit lain, serta perencanaan diit dan olah raga yang sesuai dengan pedoman untuk penderita DM.

Berdasarkan hasil analisis hubungan peran informal keluarga dengan pengendalian kadar glukosa 
darah pada pendrita diabetes mellitus di RSUD Ungaran Kabupaten Semarang, diperoleh hasil responden yang mendapatkan peran informal keluarga kategori kurang dan mempunyai pengendalian kadar glikosa darah kategori baik (12,5\%). Responden menyatakan keluarga tidak sabar dalam membimbing untuk berolahraga, tidak mengendalikan ketika minum air minum yang manis tetapi glukosa rata-rata dalam enam bulan terakhir sebear $187 \mathrm{mg} / \mathrm{dL}$, sebesar $228 \mathrm{mg} / \mathrm{dL}$, sebesar 229 $\mathrm{mg} / \mathrm{dL}$.

Kadar gula di dalam darah selalu fluktuatif bergantung pada asupan makanan. Kadar paling tinggi tercapai pada satu jam sesudah makan. Satu jam setelah makan, gula di dalam darah akan mencapai kadar paling tinggi, normalnya tidak melebihi 180 $\mathrm{mg}$ per $100 \mathrm{cc}$ darah $(180 \mathrm{mg} / \mathrm{dL})$. Kadar $180 \mathrm{mg} / \mathrm{dL}$ disebut ambang ginjal dimana ginjal bisa menahan gula pada kadar tersebut. Lebih dari angka tersebut ginjal tidak dapat menahan gula dan kelebihan gula akan keluar bersama urin, jadilah kencing yang manis (Murray et al., 2013). Menurut Fox \& Kelvert(2010), ada beberapa hal yang berhubungan dengan gula darah diantaranya olah raga.

Olah raga secara teratur dapat mengurangi resistensi insulin sehingga insulin dapat dipergunakan lebih baik oleh sel-sel tubuh. Sebuah penelitian menunjukkan bahwa peningkatan aktivitas fisik (sekitar 30 menit/hari) dapat menguranggi resiko diabetes. Olah raga juga dapat digunakan sebagai usaha untuk membakar lemak dalam tubuh sehingga dapat mengurangi berat badan bagi orang obesitas (Fox \& Kelvert, 2010).

Responden yang mendapatakan peran informal keluarga kategori baik yang mempunyai pengendalian kadar glukosa darah kategori baik $(39,6 \%)$. Responden menyatakan keluarga sering membicarakan perawatan penderita DM dengan terbuka dan menegur dengan sopan ketika melanggar advis tenaga kesehatan sehingga glukosa rata-rata dalam enam bulan terakhir sebesar 187 $\mathrm{mg} / \mathrm{dL}$,sebesar $228 \mathrm{mg} / \mathrm{dL}$, sebesar $229 \mathrm{mg} / \mathrm{dL}$

Untuk mencapai pengendalian glukosa darah yang baik, pemeriksaan darah harus sering dilakukan, karena semakin sering periksa kadar glukosa darah, maka semakin mudah pula mengatur obat agar glukosa darah bisa terkendali dengan baik (Tandra, 2010). Menurut Sukardji (2012), pengendalian kadar glukosa dipengaruhi pula oleh asupan makan.

Menurut Tandra (2008), makanan diperlukan sebagai bahan bakar dalam pembentukan ATP. Selama pencernaan, banyak zat gizi yang diabsorpsi untuk memenuhi kebutuhan energi tubuh sampai makanan berikutnya. Di dalam makanan yang dikonsumsi, terkandung karbohidrat, lemak, dan protein. Kadar gula darah sebagian tercantum pada apa yang dimakan dan oleh karenanya sewaktu makan diperlukan adanya keseimbangan diet. Mempertahankaan kadar gula darah agar mendekati nilai normal dapat dilakukan dengan asupan makanan yang seimbang sesuai dengan kebutuhan (Sukardji, 2012).

Menurut Rimbawan (2014), faktor-faktor penting dalam diet karbohidrat terhadap kenaikan kadar gula darah adalah kandungan serat dalam makanan, proses pencernaan, cara pemasakannya, ada atau tidaknya zat anti terhadap penyerapan makanan sebagai zat anti nutrient, waktu makan dengan kecepatan lambat atau cepat, pengaruh intoleransi glukosa dan pekat atau tidaknya makanan. Pasein DM 
memiliki kemampuan tubuh yang terbatas mengatur metabolisme hidrat arang dan jika toleransi hidrat arang dilampaui, pasien akan mengalami glikosuria dan ketonuria yang pada akhirnya dapat menjadi ketoasidosis, maka pembatasan kandungan hidrat arang dalam pasien DM harus dilakukan (PERKENI, 2008).

Respondan yang mendapatkan peran informal keluarga kategori baik yang mempunyai pengendalian kadar glukosa darah kategori buruk $(25,0 \%)$. Responden menyatakan keluarga sering membicarakan perawatan penderita DM dengan terbuka dan menegur dengan sopan ketika melanggar advis tenaga kesehatan tetapi glukosa rata-rata dalam enam bulan terakhir sebesar $138 \mathrm{mg} / \mathrm{dL}$, sebesar $171 \mathrm{mg} / \mathrm{dL}$, sebesar 173 $\mathrm{mg} / \mathrm{dL}$.

Kontrol DM yang buruk dapat mengakibatkan hiperglikemia dalam jangka panjang, yang menjadi pemicu beberapa komplikasi yang serius baik makrovaskular maupun mikrovaskular seperti penyakit jantung, penyakit vaskuler perifer, gagal ginjal, kerusakan saraf dan kebutaan. Banyaknya komplikasi yang mengiringi penyakit DM telah memberikan kontribusi terjadinya perubahan fisik, psikologis maupun social (Anani 2012). Pengelolaan DM yang tidak dilakukan dengan baik, khususnya dalam hal pengendalian kadar glukosa darah dapat menimbulkan komplikasi pada pembuluh darah otak, mata, jantung, ginjal dan kaki yang mengakibatkan kejadian kebutaan, gagal ginjal, penyakit karidovaskuler, stroke, serta amputasi pada kaki ( Soegondo, 2015). Menurut Fox \& Kelvert (2010), ada beberapa hal yang berhubungan dengan glukosa darah yaitu faktor usia.

Semakin bertambah usia perubahan fisik dan penurunan fungsi tubuh akan mempengaruhi lonsumsi dan penyerapan zat gizi. Berbagai penelitian menunjukkan bahwa masalah gizi pada usia lanjut sebagian besar merupakan masalah gizi berlebih dan kegemukan/obesitas yang memicu timbulnya penyakit degenerative termasuk diabetes mellitus (Maryam, Ekasari, Rosidawati, Jubaedi,\& Batubara, 2008).

Menurut Waspandji (2009), mengatakan pengawasan dan pemantauan dalam penatalaksanaan DM pada setiap saat menjadi penting. Dimana peran dari keluarga diperlukan khususnya dalam pengontrolan dan pengendalian kadar gula darah pada penderita DM. Hal ini sejalan dengan pernyataan Asdie (2000) keberhasilan penatalaksaan DM ditentukan peranan aktif dari keluarga dalam pengontrolan kadar gula darah, pencegahan komplikasi akut maupun kronik.

Keluarga sebagai suatu kelompok dapat menimbulkan, mencegah, mengabaikan atau memperbaiki masalahmasalah kesehatan keluarga itu sendiri, hampir tiap masalah kesehatan mulai dari awal sampai ke penyelesaian akan dipengaruhi oleh keluarga. Keluarga mempunyai peran utama dalam perawatan kesehatan seluruh anggota keluarga dan bukan individu sendiri yang mengusahakan tercapainya tingkat kesehatan yang diiinginkan (Friedman, 2010).

Menurut Effendi (2008), peran dan tugas setiap anggota keluarga merawat anggota keluarga yang sakit sebagai fungsi pokok keluarga secara asuh yaitu memnuhi kebutuhan dan pemeliharaan dan perawatan anggota keluarga yang sakit serta memenuhi kebutuhannya. Hal ini sejalan pendapat Rifki (2010) keluarga dengan anggota keluarga yang menderita diabetes melitus sudah tentu memerlukan perawatan terhadap 
dampak-dampak penyakit diabetes melitus yang menimbulkan ketidakmampuan pada pemenuhan kebutuhan pada individu. Peran dan tugas keluarga yang diharapkan adalah membantu dalam memberikan perawatan dan pengendalian pada pasien diabetes melitus

Menurut Friedman (2010) peran merupakan serangkaian perilaku yang diharapkan pada seseorang sesuai dengan posisi sosial yang diberikan baik secara formal maupun secara informal. Dalam peran secara informal terdapat peran keluarga merawat dan peran keluarga memotivasi.pada penelitian didapatkan peran keluarga yang paling rendah didapatkan yaitu peran keluarga merawat. Peran keluarga dalam merawat diantaranya mengenal masalah, mengambil keputusan, merawat anggota keluarga, memodifikasi lingkungan dan memanfaatkan lingkungan.

Peran keluarga dalam merawat yang tertinggi yaitu dalam mengenal masalah. Hal ini bisa dikaitkan dengan karakteristik responden pendidikan yaitu memiliki pendidikan menengah atas. Semakin tinggi pendidikan seseorang, maka semakin mudah menerima pengetahuan baru. Pendidikan merupakan salah satu faktor yang mempengaruhi peran karena makin tinggi pendidikan seseorang maka makin mudah untuk menerima informasi sehingga makin banyak pengetahuan yang dimiliki (Roshsismandoko dan Endang, 2008).

Berdasarkan penelitian pada keluarga yang memiliki peran keluarga kurang baik masih terdapat pasien diabetes melitus memiliki gula darah terkendali. Hal ini didapatkan pada pasien diabetes melitus yang sadar akan pentingnya kesehatan, dimana pasien menjaga pola makan, minum obat teratur dan melakukan olahraga secara teratur. Sedangkan pada keluarga yang memiliki peran keluarga baik masih terdapat pasien diabetes melitus memiliki gula darah tidak terkendali.

\section{Keterbatasan Penelitian}

Hasil penelitian ini tidak lepas
dari Keterbatasan dari penelitian ini adalah adanya faktor lain yang belum bisa dikendalikan sepenuhnya oleh peneliti yaitu tingkat stress yang dialami, pola makan/diet serta aktivitas fisik dimana dimungkinkan faktor tersebut juga mempengaruhi pengendalian glukosa darah penderita DM.

\section{PENUTUP}

\section{Kesimpulan}

1. Peran informal keluarga pada penderita diabetes mellitus di RSUD Ungaran Kabupaten Semarang sebagian besar kategori baik yaitu sebanyak 48 orang $(75,0 \%)$

2. Pengendalian kadar glukosa darah pada penderita diabetes mellitus di RSUD Ungaran Kabupaten Semarang sebagian besar kategori sedang yaitu sebanyak 22 orang $(34,4 \%)$.

3. Adahubungan yang bermakna peran informal keluarga dengan pengendalian kadar glukosa darah pada penderita diabetes mellitus di RSUD Ungaran Kabupaten Semarang, dengan pvalue sebesar $0,043<0,05(\alpha)$.

\section{Saran}

1. Bagai penderita diabetes mellitus Sebaiknya penderita DM lebih aktif dalam meningkatkan pengedalian glukosa dengan mematuhi diet yang ditetapkan tenaga kesehata, olahraga dengan teratur dan meneriksakan kadar glukosa sesuai dengan jadwal yang ditetapkan tenaga kesehatan.

2. Bagi masyarakat 
Sebaiknya masyarakat terutama keluarga meningkatkan komunikasi dengan penderita DM misalnya meluangkan waktu untuk berdiskusi tentang kondisi penderita sehingga motivasi penderita untuk menjalankan penatalaksanaan DM meningkat yang pada akhirnya dapat meningkatkan pengendalian kadar GD.

3. Bagi petugas kesehatan

Sebaiknya tenaga kesehatan meningkatkan pelayanan bagi penderita DM dengan aktif memberikan penyuluhan tentang penatalaksanaan penyakit DM melalui kegiatan yang sudah ada di masyarakat misalnya posyandu atau arisan.

4. Bagi Peneliti Selanjutnya

Sebaiknya meningkatkan hasil penelitian yaitu mengendalikan faktor lain yang mempengaruhi penelitian ini misalnya aktifitas olahraga, diit dan penyuluhan dengan menambahkan sebagai variabel bebas.

\section{DAFTAR PUSTAKA}

Anani, 2012. Hubungan Antara Perilaku Pengendalian Diabetes Dan Kadar Glukosa Darah Pasien Rawat Jalan Diabetes Mellitus di RSUD Arjawinangun Kabupaten Cirebon. Jurnal Kesehatan Masyarakat, Volume 1, Nomor 2, Tahun 2012, Halaman 466 - 478.

Asdie, 2010. Patogenesis dan Terapi Diabetes Mellitus Tipe 2, Yogyakarta: Medika Fakultas Kedokteran UGM.

Brunner \& Suddarth, 2012. Keperawatan Medikal Bedah. Edisi : 8 Volume 3. Jakarta : Penerbit Buku Kedokteran EGC

Effendi, 2008. Pengendalian Kadar Glukosa Darah oleh Teh Hijau atau. Teh Daun Murbai pada Tikus Diabetes. [Skripsi]. Bogor: Institut Pertanian Bogor
Fox dan Kilvert, 2010. Bersahabat dengan diabetes tipe 1. Jakarta : Penebar Plus.

Friedman, 2010. Buku Ajar Keperawatan Keluarga :Riset, Teori, dan Praktik. Jakarta : EGC.

Gefter, Rosas, Rodriguesz, Morioka Dauglas, 2013. Training at-risk youth to become diabetes selfmanagement coaches for family members: partnering family medicine residents with underserved schools. Diabetes Educ. 2014 NovDec;40(6):786-96.

Ilyas, 2015. Managemen

StrategiKeluargaSakinah, Bandung : Mandar Maju,

Meiner, 2011. Geriatric Nursing (4th ed.). Philadelphia: Mosby Elsevier

Murray et al., 2013. Biokimia Harper edisi 27. Jakarta : EGC.

Notoatmodjo, 2010. Metodologi Penelitian Kesehatan. Jakarta : Penerbit PT. Rineka Cipta.

Notoatmodjo, 2010. Promosi kesehatan dan ilmu perilaku.Jakarta: Rineka Cipta

PERKENI, 2008. Consensus Pengendalian Pencegahan Diabetes Melitus Tipe 2 di Indonesia 2011. Jakarta : Perkumpulan Endokrinologi Indonesia

Rachmawati, 2015. Hubungan Antara Konsumsi Karbohidrat dan Serat Dengan Kadar Glukosa Darah (Studi Penderita Diabetes Melitus tipe 2 Rawat Jalan di RSD KAlisat Kabupaten Jember). [Skripsi]. Jember: Universitas Jember.

Rifki, 2009. Penatalaksanaan diabetes dengan pendekatan keluarga. Penatalaksanaan diabetes mellitus 
terpadu. Jakarta: Balai Penerbit FKUI.

Sari, 2014. Peran Keluarga Dalam Merawat Klien Diabetik di Rumah. Jurnal Ners LENTERA, September 2014, vol.2, hal. 7-18.

Soegondo, 2015. Farmakoterapi pada Pengendalian Glikemia Diabetes Melitus Tipe 2 : Buku Ajar Ilmu Penyakit Dalam Jilid III Edisi V. Jakarta : Balai Penerbit Fakultas Kedokteran Universitas Indonesia.

Sukardji, 2012. Penatalaksanaan Diabetes Mellitus Terpadu. Edisi II Cetakan Ke-7. Jakarta: Fakultas Kedokteran UI

Sullivan, Bova, Johnson, Cullen, Jaffarian dan Quinn, 2014. Engaging teens and parents in collaborative practice: perspectives on diabetes self-management. Diabetes Educ. 2014 Mar-Apr;40(2):178-90.

Tandra, 2010. Life Healthy withDiabetesMengapa dan Bagaimana. Yogyakarta: CV. Andi Offset;

Tong \& Vethakkan, 2015. Why do Some People with Type 2 Diabetes Who are Using Insulin Have Poor Glycemic Control? A Qualitative Study. BMJ Open. 2015 Jan 29;5(1):e006407.

Waspandji, 2009. Komplikasi Kronik Diabetes Mekanisme Terjadinya, Diagnosis dan Strategi Pengelolaan : Buku Ajar Ilmu Penyakit Dalam Jilid III Edisi V. Balai Penerbit Fakultas Kedokteran Universitas Indonesia, Jakarta. 1134 hlm.

Wulan, 2014. Peran keluarga dan penderita DM, JNL, September 2014, vol.2, hal. 7-18. 